\title{
Quantification of microbial degradation activities in biological activated carbon filters by reverse stable isotope labelling
}

\author{
Xiyang Dong ${ }^{1,3^{*}} \mathbb{D}$, Leonard E. Bäcker ${ }^{1}$, Mona Rahmatullah', Daniel Schunk², Guido Lens \\ and Rainer U. Meckenstock ${ }^{1 *}$
}

\begin{abstract}
Biological activated carbon (BAC) filters are frequently used in drinking water production for removing dissolved organic carbon (DOC) via adsorption of organic compounds and microbial degradation. However, proper methods are still missing to distinguish the two processes. Here, we introduce reverse stable isotope labelling (RIL) for assessing microbial activity in BAC filters. We incubated BAC samples from three different BAC filters (two granular activated carbon- and one extruded activated carbon-based) in a buffer amended with ${ }^{13} \mathrm{C}$-labelled bicarbonate. By monitoring the release of ${ }^{12} \mathrm{C}_{-} \mathrm{CO}_{2}$ from the mineralization of DOC, we could demonstrate the successful application of RIL in analysing microbial DOC degradation during drinking water treatment. Changing the water flow rates through BAC filters did not alter the microbial activities, even though apparent DOC removal efficiencies changed accordingly. Microbial DOC degradation activities quickly recovered from backwashing which was applied for removing particulate impurities and preventing clogging. The size distributions of activated carbon particles led to vertical stratification of microbial activities along the filter beds. Our results demonstrate that reverse isotope labelling is well suited to measure microbial DOC degradation on activated carbon particles, which provides a basis for improving operation and design of BAC filters.
\end{abstract}

Keywords: Biological active carbon filters, Drinking water production, Dissolved organic carbon, Microbial degradation, Stable carbon isotopes

\section{Introduction}

Dissolved organic carbon (DOC) is composed of complex mixtures of heterogeneous organic compounds derived from the decay of organic matter and other sources. In drinking water production from surface water such as rivers and barrage lakes, it is important to remove the DOC because it affects the drinking water quality and performance of water treatment processes (Korotta-Gamage and Sathasivan 2017a, b; Li et al. 2017). Part of the DOC is biodegradable dissolved organic carbon $(B D O C)$ that can serve as substrate for bacterial

\footnotetext{
*Correspondence: dongxy23@mail.sysu.edu.cn; rainer. meckenstock@uni-due.de

1 Biofilm Centre, University of Duisburg-Essen, Universitätsstrasse 5,

4514 Essen, Germany

Full list of author information is available at the end of the article
}

growth in the distribution network and may be responsible for undesirable color, taste or odor of drinking water. A widely used technology for DOC removal in drinking water treatment plants is ozonation followed by activated carbon filtration (Hong et al. 2018; Korotta-Gamage and Sathasivan 2017a). The refractory fraction of DOC can be partially oxidized in the ozonation step, which greatly improves the biodegradability (von Gunten 2003). The next step is a passage through an activated carbon filter which serves both as adsorbent for the DOC and as a support for microbial growth. Thus, microorganisms can populate the activated carbon filter where they degrade the natural BDOC, but also the BDOC produced by ozonation of the total DOC.

Hence, the activated carbon (AC) filters become biological activated carbon (BAC) filters, possessing both the adsorption capacity of the $\mathrm{AC}$ and the biodegradation 
potentials of the microorganisms colonizing the surfaces and macropores of AC particles (Aryal and Sathasivan 2011; Korotta-Gamage and Sathasivan 2017a). A major benefit of the microbial degradation is the significantly prolonged lifetime of the activated carbon filters before they need to be regenerated (Gibert et al. 2013; van der Aa et al. 2011). The degradation rate of adsorbed organic carbon thus becomes an important parameter in the purification process, which is, however, mostly not measured in drinking water production plants. This is partly due to the lack of suitable and reliable methods to assess biodegradation processes on solid matrices. Nevertheless, culture-independent molecular tools have shown that highly diverse microbial communities of bacteria and archaea populate BAC filters (Gulay et al. 2016; Vignola et al. 2018).

Most of the recent studies could only indirectly describe microbial activities on AC filters by measuring e.g. biomass densities (Fonseca et al. 2001), adenosine triphosphate (ATP) content (Gibert et al. 2013; Velten et al. 2007), or quantifying microbial cells with epifluorescence microscopy (EFM) or flow-cytometry (Vignola et al. 2018). So far, only a few laborious and cost-ineffective methods can directly determine the microbial activity of biofilms (i.e. organic compound degradation rates) on activated carbon particles, e.g. by monitoring bacterial uptake of labelled substrates or consumption of dissolved oxygen using a respirometric method (Servais et al. 1991; Urfer and Huck 2001). Very sensitive options to assess biodegradation are stable isotope-based methods, which employ either fully or partially labelled substrates such as ${ }^{13} \mathrm{C}$-glucose (Saito et al. 1996; Schmidt et al. 2004). If the compound is biodegraded, it is converted to ${ }^{13} \mathrm{CO}_{2}$ which leads to changes of the ${ }^{13} \mathrm{C} /{ }^{12} \mathrm{C}$ carbon isotope ratios of the total $\mathrm{CO}_{2}$ and the carbonate system. Such a change of the stable isotope ratio therefore indicates the mineralization of the substrate, which can be used to calculate biodegradation rates. However, only a few ${ }^{13} \mathrm{C}$-labeled substrates such as glucose and acetate are commercially available, but they cannot represent the complexity of DOC. Complex substrates, however, cannot be labelled which has hindered the wide use of stable isotope technologies in determining microbial degradation rates in BAC filters, so far.

Dong et al. (2017) presented a simple and cost-effective method for evaluating microbial mineralization of any kind of organic carbon to $\mathrm{CO}_{2}$ by reverse stable isotope labelling (RIL). The method is based on adding ${ }^{13} \mathrm{C}$-labelled bicarbonate buffer to the incubation medium at a molar ratio of approximately ten atom percent. Since the degradation of non-labelled organic carbon leads to the evolution of ${ }^{12} \mathrm{CO}_{2}$, the ${ }^{13} \mathrm{C}$-stable isotope ratio of the total inorganic carbon (TIC) in the system drops accordingly. Microbial mineralization rates can thus be derived following mass-balance calculations (Dong et al. 2017; Schulte et al. 2019). The advantage of the reverse stable isotope labelling lies in the high sensitivity and precision of ${ }^{13} \mathrm{CO}_{2} /{ }^{12} \mathrm{CO}_{2}$ measurements with stable isotope ratio analysis allowing for the detection of very small amounts of $\mathrm{CO}_{2}$ evolution. Furthermore, one can use this sensitive technology without the need of applying stable isotope-labelled organic compounds, which are often extremely expensive.

Here, we evaluate the use of reverse stable isotope labelling (RIL) to assess the degradation of adsorbed organic carbon in activated carbon filters for drinking water production. The biodegradable fraction of the organic carbon was measured as released $\mathrm{CO}_{2}$ (Korotta-Gamage and Sathasivan 2017a, b). As examples for the applicability of RIL in monitoring biodegradation in BAC filters, we demonstrate the effects of typical water operations, such as backwashing and different BAC filter materials, on microbial activities and removal of organic carbon.

\section{Materials and methods Setup of BAC filters}

We used three parallel BAC filters (BAC filters 1-3) belonging to a test facility (RWW, Rheinisch-Westfälische Wasserwerksgesellschaft mbH, Mülheim, Germany) treating raw water from River Ruhr for drinking water production. In the water production facility, the river water is firstly filtered by slow sand filtration where labile organic carbon is removed, followed by ozonation where the DOC is oxidized and becomes more bioavailable. After ozonation, the water runs through three parallel multilayer filters that remove particulate impurities. Each multilayer filter is connected to one BAC filter, respectively. BAC filters 1 and 2 were filled with fresh, heterogeneously sized granular activated carbon (GAC) NORIT $^{\circledR}$ GAC 830 (Cabot Corporation, USA) and filter 3 with fresh, evenly sized extruded activated carbon (EAC) NORIT ${ }^{\circledR}$ ROW 0.8 Supra (Cabot Corporation, USA).

The three BAC filters had identical reactor volumes (20 cm diameter, $200 \mathrm{~cm}$ height) and each of them was divided into two phases, the upper surface water part and the lower BAC filter bed. They had different activated carbon bed depths, i.e. filter 1: $40 \mathrm{~cm}$ upper water $+160 \mathrm{~cm}$ GAC particles; filter 2: $25 \mathrm{~cm}$ upper water $+175 \mathrm{~cm}$ GAC particles; and filter 3: $55 \mathrm{~cm}$ upper water $+145 \mathrm{~cm}$ EAC particles. The filters were percolated with the pretreated water from top to bottom. Correspondingly, the empty bed contact times (EBCT) were $\sim 10 \mathrm{~min}, \sim 18 \mathrm{~min}$, and $\sim 15 \mathrm{~min}$, respectively (if not specified). The $\mathrm{pH}$ of the inflow water was around 7.15 and the temperature $18.6^{\circ} \mathrm{C}$. 


\section{RIL experiments}

Activated carbon was sampled from the surface of the three filter beds at several intervals. Since the BAC filters were operated indoors, the inflow water temperatures did not significantly change during the whole experiments. At the end of the experiment, activated carbon was sampled at various depths of the filter beds $(0 \mathrm{~cm}, 20 \mathrm{~cm}$, $40 \mathrm{~cm}, 80 \mathrm{~cm}$, and $140 \mathrm{~cm}$, measured from the top of the activated carbon bed) in order to determine the vertical distribution of microbial activity. The activated carbon particles ( $3 \mathrm{~g}$ wet weight each) were transferred to three replicate $250 \mathrm{~mL}$ serum bottles filled with $50 \mathrm{~mL}$ influent water. A large air headspace $(200 \mathrm{~mL})$ ensured oxic conditions in the bottles. For each microcosm, $\mathrm{NaH}^{13} \mathrm{CO}_{3}$ and $\mathrm{NaH}^{12} \mathrm{CO}_{3}$ (Sigma-Aldrich Co.) at a molar ratio of 10:90 were injected separately through the stopper to produce a final concentration of $10 \mathrm{mM}$ bicarbonate in the medium. Addition of such amounts of bicarbonate did not change the initial $\mathrm{pH}$ values of the water. The organic carbon in each microcosm mostly originated from the DOC adsorbed to the activated carbon particles during the prior operation and to a smaller extent from the DOC dissolved in the used water. All bottles were incubated for at least $24 \mathrm{~h}$ at $17^{\circ} \mathrm{C}$ in the dark to mimic the temperature conditions of the AC filters.
Germany) which was also used as working reference gas. The $\delta^{13} \mathrm{C}$ values were reported as average of $5 \mathrm{~min}$ measurements.

\section{Calculations of microbial activities}

By artificially elevating the background isotopic abundances of ${ }^{13} \mathrm{CO}_{2}$, a release of ${ }^{12} \mathrm{CO}_{2}$ can be detected as a change of the ${ }^{12} \mathrm{C} /{ }^{13} \mathrm{C}$-isotope ratio. Mass-balance equations allow then to calculate the amount of released $\mathrm{CO}_{2}$ over time.

All carbon isotope ratios $\left({ }^{13} \mathrm{C} /{ }^{12} \mathrm{C}\right.$, referred to as $\left.R\right)$ obtained from IRIS were reported in conventional delta notation $\left(\delta^{13} \mathrm{C}\right)$ as per mil (\%) values, relative to the Vienna Pee Dee Belemnite (VPDB) standard (Eq. 1).

$$
\delta^{13} C=\frac{R_{\text {sample }}}{R_{V P D B}}-1
$$

where 0.0111802 is the ratio of ${ }^{13} \mathrm{C} /{ }^{12} \mathrm{C}$ in the VPDB standard. To facilitate the comparison of results which are obtained from samples highly enriched in ${ }^{13} \mathrm{C}$, all carbon isotope ratios were converted into ${ }^{13} \mathrm{C}$ atom fractions $\left(x\left({ }^{13} \mathrm{C}\right)\right)$ [\%] from $\delta^{13} \mathrm{C}$ values (Coplen 2011).

$\mathrm{CO}_{2}$ production was calculated from changes in carbon isotope ratios based on isotope mass balance consideration (Eq. 2) (Dong et al. 2017; Schulte et al. 2019).

$$
C O_{2 \text { produced }}=\frac{\left(\mathrm{CO}_{2 \text { bicarbonate solution }}+\mathrm{CO}_{2 \text { natural }}+\mathrm{CO}_{2 \text { air }}\right) \times\left(x\left({ }^{13} \mathrm{C}\right)_{\text {background }}-x\left({ }^{13} \mathrm{C}\right)_{\text {total }}\right)}{x\left({ }^{13} \mathrm{C}\right)_{\text {total }}-x\left({ }^{13} \mathrm{C}\right)_{\text {produced }}}
$$

\section{Isotope Ratio Mid-Infrared Spectroscopy (IRIS)}

Carbon isotope ratios of $\mathrm{CO}_{2}$ were measured as described previously (Dong et al. 2017). Briefly, liquid samples $(0.5 \mathrm{~mL})$ were taken with a syringe through the stopper of the incubation bottles and injected into closed $12 \mathrm{~mL}$ Labco Exetainer vials (Labco Limited, Lampeter, Wales, UK.). The vials were pre-filled with $85 \%$ phosphoric acid $(50 \mu \mathrm{L})$ and flushed with $\mathrm{CO}_{2}$-free synthetic air $\left(\mathrm{CO}_{2}<0.1 \mathrm{ppm}\right.$, Air Liquide, Oberhausen, Germany). Then, the liberated $\mathrm{CO}_{2}$ gas in the headspace of these samples was analyzed using a Thermo Fisher Delta Ray $\mathrm{CO}_{2}$ Isotope Ratio Infrared Spectrometer (IRIS) with Universal Reference Interface (URI) Connect (Dong et al. 2017; Fischer and Lopez 2016). IRIS is capable of measuring both carbon and oxygen isotope compositions of $\mathrm{CO}_{2}$ by comparing various $\mathrm{CO}_{2}$ isotopologues of the sample in air (i.e. ${ }^{12} \mathrm{C}^{16} \mathrm{O}^{16} \mathrm{O},{ }^{13} \mathrm{C}^{16} \mathrm{O}^{16} \mathrm{O}$, and ${ }^{12} \mathrm{C}^{16} \mathrm{O}^{18} \mathrm{O}$ ) (van Geldern et al. 2014). Before measurements, the IRIS was calibrated using two $\mathrm{CO}_{2}$ reference gases for carbon isotope ratios: one with $\delta^{13} \mathrm{C}$ values of $-9.7 \%$ $\left[x\left({ }^{13} \mathrm{C}\right)=1.10 \%\right.$, Thermo Fisher, Bremen, Germany $]$ and the other with $x\left({ }^{13} \mathrm{C}\right)=10 \%$ (Sigma-Aldrich, Taufkirchen, where $\mathrm{CO}_{2 \text { background }}$ is the initial amount of total inorganic carbon in the system $[\mathrm{mmol}], \mathrm{CO}_{2 \text { produced }}$ is the $\mathrm{CO}_{2}$ released from microbial mineralization of DOC [mmol], $x\left({ }^{13} \mathrm{C}\right)_{\text {total }}$ is the final carbon isotope ratio of the total inorganic carbon in the system, $x\left({ }^{13} C\right)_{\text {background }}$ is the initial carbon isotope ratio of total inorganic carbon in the system, $x\left({ }^{13} \mathrm{C}\right)_{\text {produced }}$ is the carbon isotope ratio of $\mathrm{CO}_{2}$ released by microbial production [assumed to be $1.1 \%$ based on the abundance of ${ }^{13} \mathrm{C}$ in nature (Aelion

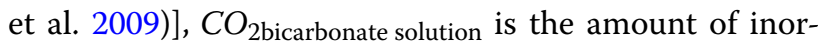
ganic carbon in the added bicarbonate solution [mmol], $\mathrm{CO}_{2 \text { natural }}$ is the amount of inorganic carbon in the inoculum [mmol], $\mathrm{CO}_{2 \text { air }}$ is the amount of inorganic carbon in the headspace [mmol].

A comparison of different fitting models revealed that a second-degree polynomial matched the $\mathrm{CO}_{2}$ production curves (i.e. mineralized DOC) based on measurements at more than five time intervals in the first $24 \mathrm{~h}$ of incubation. The slopes of the regression curves were further normalized per liter of volume of BAC filters and provided as the microbial degradation rates. 


\section{Analytical methods}

DOC concentrations in water samples were determined using a total organic carbon analyzer (Shimadzu TOC-V $\mathrm{CPN}$ ) equipped with an auto sampler (Model ASI-V, Shimadzu). For a rough estimation of the total cell counts on the activated carbon samples, detachment of bacteria was performed with a Tween-80 solution (Fluka, 0.1\% final concentration) via $5 \mathrm{~min}$ ultrasonication and $3 \mathrm{~min}$ vortex. The detached bacteria were then filtered through polycarbonate filters with a pore size of $0.22 \mu \mathrm{m}$ followed by DAPI $\left(4^{\prime}, 6\right.$-diamidino-2-phenylindole) staining and visual enumeration with fluorescence microscopy (Lunau et al. 2005).

\section{Results}

\section{Effect of AC types on microbial activities}

During the summer period from May to August 2016 (110 days), the DOC concentrations in the influent waters of the three BAC filters ranged from 0.89 to $1.03 \mathrm{mg} / \mathrm{L}$ (Fig. 1). DOC concentrations were higher during the winter period from December 2016 to January 2017 (42 days) ranging from 1.03 to $1.20 \mathrm{mg} / \mathrm{L}$. The increased DOC in autumn and winter is a common phenomenon caused by e.g. decay of fallen leaves.

The removal of DOC by the BAC filters developed in three stages (Korotta-Gamage and Sathasivan 2017a; Simpson 2008). At the start of the experiment, a significant reduction of around $0.8 \mathrm{mg} / \mathrm{L}$ DOC between influent and effluent was observed for all filters (Fig. 1). This first phase (days 0-33) can be interpreted as a strong physical adsorption. As the filter bed size of filter 3
(145 cm) was 10 and $20 \%$ smaller compared to filters 1 and $2(160$ and $175 \mathrm{~cm})$, the DOC adsorption rate of filter 3 per volume of extruded activated carbon was much higher than of granular activated carbon in filters 1 and 2 .

In the second phase (days 33-61), removal of DOC leveled off which is explained by a gradual saturation of adsorption sites and concurrent establishing of biological degradation. After around 61 days, the third steady state phase started, when around $\sim 25 \%$ DOC was removed by all three filters regardless of the types of activated carbon. The DOC reduction at this steady stage is mainly attributed to microbial degradation but also to stable adsorption, which, however, are difficult to distinguish (Gibert et al. 2013; Korotta-Gamage and Sathasivan 2017b).

During the third phase (days 82-95), activated carbon samples were taken from the top surface of the filter beds to determine both biomass densities and DOC degradation activities represented as $\mathrm{CO}_{2}$ production rates. At the first two sampling days, the degradation activities per liter in filters 1 and 2 (filled with granular activated carbon) were equal at around $4.8 \mathrm{mg} / \mathrm{h}$, while the material taken from filter 3 (filled with extruded activated carbon) showed $\sim 1.2$ times higher degradation rates of $5.8 \mathrm{mg} / \mathrm{h}$ (Fig. 2). This disagrees with similar bacterial densities in the three filters (Table 1) and might be related to the higher adsorption kinetic and specific capacity of the extruded activated carbon.

\section{Spatial distributions of microbial activities}

At the end of the experiment (Day 258), we sacrificed the reactors and sampled activated carbon at different

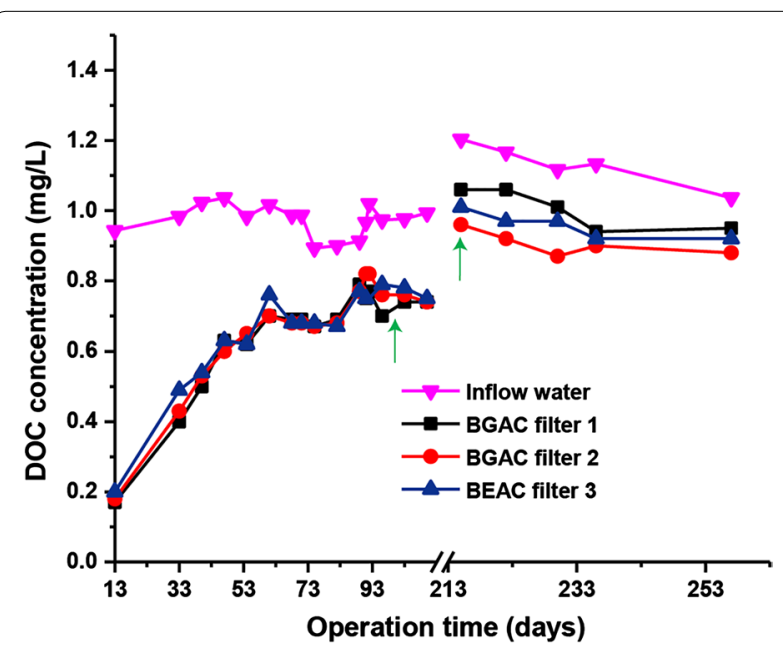

Fig. 1 Influent and effluent DOC concentrations of the three BAC filters during two-time periods: I. summer period since May 2016 for 110 days (Day 0-Day 110) and II. winter period since December 2016 for 42 days (Day 215-Day 255). Arrows indicate the backwashing at Day 96 and changing of flow rates at Day 215, respectively

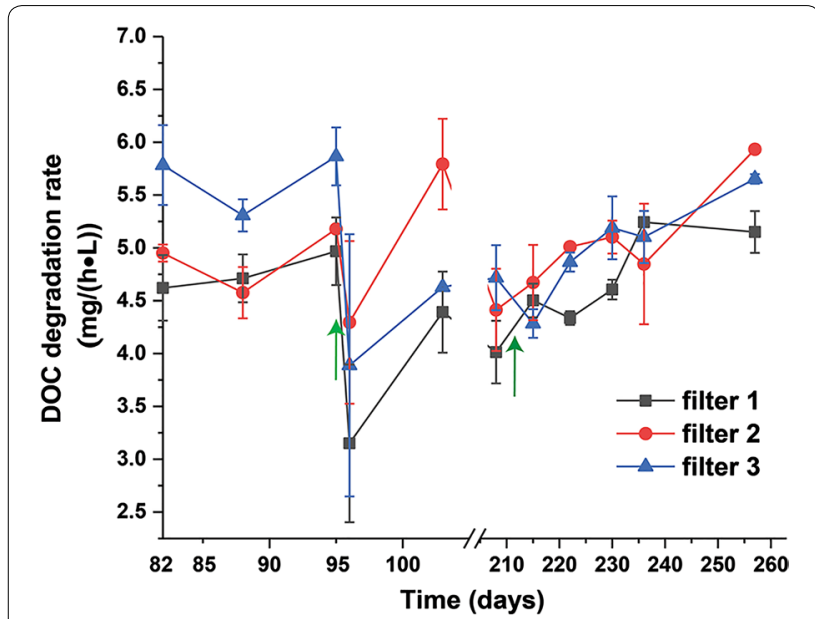

Fig. 2 Effect of backwashing and flow rate on microbial degradation rates in BAC filters. Data depict means and standard deviations of three parallel incubations for RIL. Arrows indicate the backwashing at Day 96 and changing of flow rates at Day 208. Filters 1 and 2 are filled with granular activated carbon whereas filter 3 is filled with extruded activated carbon 
Table 1 Total cell count per liter volume of the three BAC filters

\begin{tabular}{llll}
\hline Day & \multicolumn{3}{l}{ Cell number $\mathbf{( 1 \mathbf { 1 } ^ { \mathbf { 1 1 } } \mathbf { L } )}$} \\
\cline { 2 - 4 } & Filter $\mathbf{1}$ & Filter $\mathbf{2}$ & Filter $\mathbf{3}$ \\
\hline 82 & $7.7 \pm 1.8$ & $7.3 \pm 2.6$ & $7.4 \pm 1.2$ \\
88 & $8.1 \pm 2.7$ & $7.3 \pm 1.0$ & $7.4 \pm 0.8$ \\
95 & $8.6 \pm 1.4$ & $7.3 \pm 1.0$ & $8.2 \pm 1.6$ \\
96 & $4.5 \pm 0.9$ & $4.7 \pm 1.0$ & $4.3 \pm 0.8$ \\
103 & $8.6 \pm 2.3$ & $7.8 \pm 2.6$ & $7.0 \pm 1.6$ \\
\hline
\end{tabular}

The biomass densities were measured from activated carbon samples taken from the top surface of the filter beds. Data show means of three replicates \pm standard deviation. Filters 1 and 2 were filled with granular activated carbon whereas filter 3 was filled with extruded activated carbon

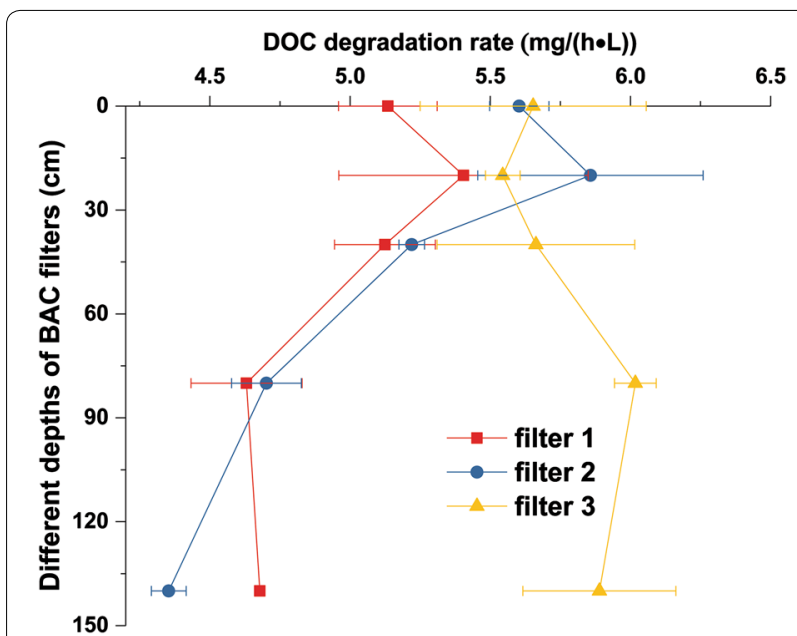

Fig. 3 Microbial DOC degradation rates as a function of depth in the BAC filters. Depth 0 corresponds to the top of the filter bed. Data depict means and standard deviations of three parallel incubations. Filters 1 and 2 are filled with granular activated carbon whereas filter 3 is filled with extruded activated carbon

depths to characterize the spatial distribution of microbial activities along the filter beds. In BAC filters 1 and 2 , the highest microbial activities were found at the second sampling point located $20 \mathrm{~cm}$ below the top surface layer ( 5.4 and $5.9 \mathrm{mg} \mathrm{CO}-\mathrm{C} /(\mathrm{h} \mathrm{L})$, respectively). They decreased by $14 \%$ and $26 \%$ to the bottom of filters 1 and 2 , respectively (Fig. 3 ).

\section{Effect of flow rates on microbial activities}

In order to test if transport of DOC to the microorganisms on the BAC particles limits the biodegradation activity, we changed the flow rates of the three filters (Fig. 1). At day 208 (data not shown), the flow rate of filter 1 was increased from 300 to $450 \mathrm{~L} / \mathrm{h}$, the flow rate of filter 2 was decreased to $150 \mathrm{~L} / \mathrm{h}$, while filter 3 remained unchanged at $300 \mathrm{~L} / \mathrm{h}$. The DOC removal by the three filters showed clear responses to changing flow rates, with corresponding removal efficiencies of filter 3 remaining at around $16 \%$, filter 1 decreasing to $12 \%$ and filter 2 increasing to $20 \%$ after 1 week (at day 215) (Fig. 1), respectively. This systematic change indicates that longer contact times of the water (lower flow rate) to the BAC increased the removal of organic matter.

\section{Effect of backwashing on microbial activities}

At Day 96, our filters were backflushed twice (5-6 min each) using clean drinking water at flow velocities of 2.8$3.2 \mathrm{~m} / \mathrm{h}$. After backwashing, cell numbers of the filters 1 , 2 , and 3 , decreased by $45 \%, 33 \%$, and $43 \%$, respectively (Table 1). Similarly, the $\mathrm{CO}_{2}$ production rates declined by $36 \%, 17 \%$, and $33 \%$, respectively (Fig. 2). Only 1 week later, both parameters fully recovered to values before backwashing.

\section{Discussion}

So far, there are only indirect methods available to measure microbial degradation activities of organic carbon adsorbed to solid matrices. Here, we demonstrated that reverse isotope labelling (RIL) can be applied to directly monitor microbial degradation activities and DOC removal efficiencies for biological activated carbon (BAC) filters of a drinking water treatment plant. To this end, we applied reverse stable isotope labelling (RIL) for assessing minute rates of microbial $\mathrm{CO}_{2}$ release (Dong et al. 2017). With the aid of mid-infrared laser spectroscopy, we comprehensively demonstrated effects of AC types, spatial distributions, flow rates, and backwashing on microbial activities in BAC filters.

\section{Effects of AC types}

The data (Fig. 1 and Table 1) indicate that the microorganisms in filter 3 had much more adsorbed organic substrate available per liter volume of $\mathrm{AC}$, most likely originating from the better adsorption process of the extruded AC. This observation suggests that the DOC removal efficiencies were not only affected by the adsorption/desorption equilibrium of DOC to the respective AC material (Korotta-Gamage and Sathasivan 2017b; Yapsakli and Cecen 2010), but also by the correlated support of the microorganisms with organic substrate for biodegradation.

\section{Spatial distributions of microbial activities}

The distribution of the DOC mineralization potential (Fig. 3) may be related to a stratification of different sizes of the activated carbon particles. This is because microorganisms are mostly located on the fine particles fraction (Urfer and Huck 2001). Similar observations were 
made for many column experiments and were attributed to the degradation of the organic substrate and growth of the microorganisms towards the inlet (Gibert et al. 2013; Velten et al. 2011). Indeed, the regular backwashing of the two filters 1 and 2 resulted in an accumulation of smaller particles in the upper parts (Frank et al. 2015). Hence, it seems that the fine particles of NORIT ${ }^{\circledR}$ GAC 830 lead to a higher DOC removal either due to the smaller physical size and better solute transport properties to the attached biomass or due to a higher accumulation of biomass on smaller particles (Velten et al. 2007). For filter 3, filled with the extruded activated carbon, we observed an almost constant microbial activity along the filter depth. Since the extruded activated carbon had a very homogeneous size distribution of the particles with a round and compact shape and no fines, this type of activated carbon did not undergo a physical size separation during backwashing. We therefore attribute the gradient of microbial activity in filters 1 and 2 to the size distribution of the activated carbon particles rather than to an effect of enhanced growth at the filter inlet. Thus, the material of filter 3 showed superior properties for a more homogenous distribution of microbial activity and filter performance. The spatial distributions of microbial activities may be also related to oxygen gradients along the filters. This is because microbial DOC degradation would consume up oxygen at the near inflow site. Microbes that live far from the inflow site would be limited by oxygen availability, leading to the decrease in microbial activities.

\section{Effect of flow rates}

Changing the flow rates led to only small differences in the microbial degradation activity measured with RIL (Fig. 2) indicating that the microbial degradation activities in our experiments are limited by the desorption rates of organic carbon from the BAC particles or the microbial biomass that established on the AC. This aligns with other studies indicating that the biodegradation reaction time on the filters could be an important limiting factor for DOC removal (Pramanik et al. 2015).

\section{Effect of backwashing}

Backwashing is important to avoid clogging of AC filters during long-term operation in drinking water production (Kim et al. 2014). However, it is not known if the removal of biomass during backwashing impairs the microbial degradation properties of the bio filters. In our experiments, the performances of microbial activities recovered in 1 week (Fig. 2). This suggested that the backwashing reduced the DOC degradation activity because microbes were washed out (Frank et al. 2015; Kim et al. 2014).
Nevertheless, the filter functions were mostly maintained and recovered quickly.

Overall, we showed that degradation of organic carbon adsorbed to solid particles could be well assessed by measuring $\mathrm{CO}_{2}$ development or mineralization rates with RIL. This is especially interesting for quantifying DOC degradation on activated carbon, which is a strong adsorbent prohibiting the determination of substrate concentrations. Since adsorption does not lead to $\mathrm{CO}_{2}$ production, the RIL method allowed distinguishing adsorption and biodegradation in complex environmental processes. This can be used to analyse microbial activities from environmental samples or to improve technical processes such as activated carbon filtration by e.g. identifying if biodegradation processes are limiting DOC removal efficiencies. The easy analysis of the RIL with bench top analytical instruments provides a reliable and comparable way to quantify degradation processes on solid matrices such as activated carbon. Compared to other methods for assessing degradation activities that deliver only relative units, RIL provides degradation rates in $\mathrm{mg} \mathrm{CO}_{2} /(\mathrm{L} \mathrm{h})$, which makes such data comparable between different laboratories and allows quantifying and calculating mass balances.

\section{Acknowledgements \\ Not applicable.}

\section{Authors' contributions}

XD and RUM designed the study. LEB, MR, DS, GL performed experiments. XD, $L E B, M R$ and RUM performed data analysis. XD and RUM drafted the manuscript. All authors reviewed the results and participated in the writing of the manuscript. All authors read and approved the final manuscript.

\section{Funding}

R.U. M. acknowledges funding from the H2020 ERC advanced grant ECOILogy (No. 666952).

\section{Availability of data and materials}

The authors declare that all data supporting the findings of this study are available within the article and its supplementary information files, or from the corresponding authors upon request.

Ethics approval and consent to participate Not applicable.

Consent for publication

Not applicable.

Competing interests

The authors declare that they have no competing interests.

\section{Author details}

${ }^{1}$ Biofilm Centre, University of Duisburg-Essen, Universitätsstrasse 5, 4514 Essen, Germany. ${ }^{2}$ RWW Rheinisch-Westfälische Wasserwerksgesellschaft mbH, Am Schloß Broich 1-3, 45479 Mülheim, Germany. ${ }^{3}$ Present Address: School of Marine Sciences, Sun Yat-Sen University, Zhuhai 519000, China.

Received: 14 March 2019 Accepted: 29 June 2019

Published online: 16 July 2019 


\section{References}

Aelion CM, Höhener P, Hunkeler D, Aravena R (2009) Environmental isotopes in biodegradation and bioremediation. CRC Press, Boca Raton

Aryal A, Sathasivan A (2011) Importance of the order in enhancing EfOM removal by combination of BAC and MIEX((R)). Water Sci Technol 64(11):2325-2332

Coplen TB (2011) Guidelines and recommended terms for expression of stable-isotope-ratio and gas-ratio measurement results. Rapid Commun Mass Spectrom 25(17):2538-2560

Dong X, Jochmann MA, Elsner M, Meyer AH, Backer LE, Rahmatullah M, Schunk D, Lens G, Meckenstock RU (2017) Monitoring microbial mineralization using reverse stable isotope labeling analysis by mid-infrared laser spectroscopy. Environ Sci Technol 51(20):11876-11883

Fischer TP, Lopez TM (2016) First airborne samples of a volcanic plume for $\delta^{13} \mathrm{C}$ of $\mathrm{CO}_{2}$ determinations. Geophys Res Lett 43(7):3272-3279

Fonseca AC, Summers RS, Hernandez MT (2001) Comparative measurements of microbial activity in drinking water biofilters. Water Res 35(16):3817-3824

Frank J, Ruhl AS, Jekel M (2015) Impacts of backwashing on granular activated carbon filters for advanced wastewater treatment. Water Res 87:166-174

Gibert O, Lefevre B, Fernandez M, Bernat X, Paraira M, Calderer M, MartinezLlado X (2013) Characterising biofilm development on granular activated carbon used for drinking water production. Water Res 47(3):1101-1110

Gulay A, Musovic S, Albrechtsen HJ, Al-Soud WA, Sorensen SJ, Smets BF (2016) Ecological patterns, diversity and core taxa of microbial communities in groundwater-fed rapid gravity filters. ISME J 10(9):2209-2222

Hong S, Xian-Chun T, Nan-Xiang W, Hong-Bin C (2018) Leakage of soluble microbial products from biological activated carbon filtration in drinking water treatment plants and its influence on health risks. Chemosphere 202:626-636

Kim TG, Yun J, Hong SH, Cho KS (2014) Effects of water temperature and backwashing on bacterial population and community in a biological activated carbon process at a water treatment plant. Appl Microbiol Biotechnol 98(3):1417-1427

Korotta-Gamage SM, Sathasivan A (2017a) Potential and challenges of biologically activated carbon to remove natural organic matter in drinking water purification process. Chemosphere 167:120-138

Korotta-Gamage SM, Sathasivan A (2017b) Potential of a biologically activated carbon treatment to remove organic carbon from surface waters. Int Biodeter Biodegr 124:82-90

Li C, Wang D, Xu X, Xu M, Wang Z, Xiao R (2017) Tracking changes in composition and amount of dissolved organic matter throughout drinking water treatment plants by comprehensive two-dimensional gas chromatography-quadrupole mass spectrometry. Sci Total Environ 609:123-131

Lunau M, Lemke A, Walther K, Martens-Habbena W, Simon M (2005) An improved method for counting bacteria from sediments and turbid environments by epifluorescence microscopy. Environ Microbiol 7(7):961-968
Pramanik BK, Roddick FA, Fan LH (2015) A comparative study of biological activated carbon, granular activated carbon and coagulation feed pre-treatment for improving microfiltration performance in wastewater reclamation. J Membrane Sci 475:147-155

Saito T, Hanaki K, Matsuo T (1996) Mechanism of anaerobic biological activated carbon process examined by using stable isotope. Water Sci Technol 34(5-6):429-435

Schmidt TC, Zwank L, Elsner M, Berg M, Meckenstock RU, Haderlein SB (2004) Compound-specific stable isotope analysis of organic contaminants in natural environments: a critical review of the state of the art, prospects, and future challenges. Anal Bioanal Chem 378(2):283-300

Schulte SM, Köster D, Jochmann MA, Meckenstock RU (2019) Applying reverse stable isotope labeling analysis by mid-infrared laser spectroscopy to monitor BDOC in recycled wastewater. Sci Total Environ 665:1064-1072

Servais P, Billen G, Ventresque C, Bablon GP (1991) Microbial activity in GAC filters at the Choisy-Le-Roi treatment-plant. J Am Water Works Assoc 83(2):62-68

Simpson DR (2008) Biofilm processes in biologically active carbon water purification. Water Res 42(12):2839-2848

Urfer D, Huck PM (2001) Measurement of biomass activity in drinking water biofilters using a respirometric method. Water Res 35(6):1469-1477

van der Aa LTJ, Rietveld LC, van Dijk JC (2011) Effects of ozonation and temperature on the biodegradation of natural organic matter in biological granular activated carbon filters. Drink Water Eng Sci 4(1):25-35

van Geldern R, Nowak ME, Zimmer M, Szizybalski A, Myrttinen A, Barth JA, Jost HJ (2014) Field-based stable isotope analysis of carbon dioxide by midinfrared laser spectroscopy for carbon capture and storage monitoring. Anal Chem 86(24):12191-12198

Velten S, Hammes F, Boller M, Egli T (2007) Rapid and direct estimation of active biomass on granular activated carbon through adenosine triphosphate (ATP) determination. Water Res 41(9):1973-1983

Velten S, Boller M, Koster O, Helbing J, Weilenmann HU, Hammes F (2011) Development of biomass in a drinking water granular active carbon (GAC) filter. Water Res 45(19):6347-6354

Vignola M, Werner D, Hammes F, King LC, Davenport RJ (2018) Flow-cytometric quantification of microbial cells on sand from water biofilters. Water Res 143:66-76

von Gunten U (2003) Ozonation of drinking water: part I. Oxidation kinetics and product formation. Water Res 37(7):1443-1467

Yapsakli K, Cecen F (2010) Effect of type of granular activated carbon on DOC biodegradation in biological activated carbon filters. Process Biochem 45(3):355-362

\section{Publisher's Note}

Springer Nature remains neutral with regard to jurisdictional claims in published maps and institutional affiliations.

\section{Submit your manuscript to a SpringerOpen ${ }^{\circ}$ journal and benefit from:}

- Convenient online submission

- Rigorous peer review

- Open access: articles freely available online

- High visibility within the field

Retaining the copyright to your article

Submit your next manuscript at springeropen.com 